\title{
Influence of Paleolithic diet on anthropometric markers in chronic diseases: systematic review and meta- analysis
}

Ehrika Vanessa Almeida de Menezes ${ }^{1,2}$, Helena Alves de Carvalho Sampaio ', Antônio Augusto Ferreira Carioca ${ }^{2,3}$, Nara Andrade Parente ${ }^{1,2^{*}}$ (D), Filipe Oliveira Brito ${ }^{1,2}$, Thereza Maria Magalhães Moreira ${ }^{1,4}$,

Ana Célia Caetano de Souza ${ }^{5,6}$ and Soraia Pinheiro Machado Arruda ${ }^{7,8}$

\begin{abstract}
Background: The Paleolithic diet has been studied in the scope of prevention and control of chronic noncommunicable diseases (CNCD). The objective of this study was to analyze the influence of the Paleolithic diet on the prevention and control of CNCD in humans, specifically on anthropometric markers, through a systematic review with meta-analysis.

Methods: What is the effect of the Paleolithic diet on anthropometric parameters (weight, body mass index and waist circumference) compared to other control diets based on recommendations in adults? We included only randomized studies with humans that used the Paleolithic Diet in the prevention and control of CNCD published in Portuguese, English or Spanish. The search period was until March 2019, in the LILACS, PubMed, Scielo, Science Direct, Medline, Web of Science and Scopus databases. The abstracts were evaluated by two researchers. We found 1224 articles, of which 24 were selected and 11 were included in the meta-analysis. The effect of dietary use on body weight, body mass index and waist circumference was evaluated.

Results: The summary of the effect showed a loss of $-3.52 \mathrm{~kg}$ in the mean weight (Cl 95\%: $-5.26 ;-1.79 ; p<0,001$; $\mathrm{I}^{2}=24 \%$ ) of people who adopted the Paleolithic diet compared to diets based on recommendations. The analysis showed a positive association of adopting the Paleolithic diet in relation to weight loss. The effect was significant on weight, body mass index and waist circumference.
\end{abstract}

Conclusion: The Paleolithic diet may assist in controlling weight and waist circumference and in the management of chronic diseases. However, more randomized clinical studies with larger populations and duration are necessary to prove health benefits.

Trial registration: $C R D 42015027849$.

Keywords: Paleolithic diet, Anthropometry, Obesity, Systematic review, Meta-analysis

\footnotetext{
* Correspondence: naradeandrade@gmail.com

${ }^{1}$ Postgraduate Program in Colletive Health, Universidade Estadual do Ceará (UECE), Fortaleza, Brazil

${ }^{2}$ Nutrition course, Universidade de Fortaleza (UNIFOR), Fortaleza, Brazil

Full list of author information is available at the end of the article
}

(c) The Author(s). 2019 Open Access This article is distributed under the terms of the Creative Commons Attribution 4.0 International License (http://creativecommons.org/licenses/by/4.0/), which permits unrestricted use, distribution, and reproduction in any medium, provided you give appropriate credit to the original author(s) and the source, provide a link to the Creative Commons license, and indicate if changes were made. The Creative Commons Public Domain Dedication waiver (http://creativecommons.org/publicdomain/zero/1.0/) applies to the data made available in this article, unless otherwise stated. 


\section{Introduction}

Chronic noncommunicable diseases (CNCDs) are a matter of great concern to the world public health and the leading cause of death. In 2005, around 35 million deaths were attributed to such diseases, almost $60 \%$ of global mortality and $45.9 \%$ of the global burden of diseases [1]. If this trend is maintained, it is estimated that by 2020 CNCDs will account for $73 \%$ of deaths and $60 \%$ of disease burden [2].

According to the World Health Organization - WHO (2014) [1], CNCDs include cancer, diabetes, chronic respiratory disease, and cardiovascular diseases. According to the Institute of Medicine - IOM (2012) [3], CNCDs correspond to a larger group of diseases given the conditions grouped together (arthritis, cancer survivors, chronic pain, dementia, depression, type 2 diabetes mellitus, post traumatic disability conditions, schizophrenia and loss of sight and hearing) that characterize as chronic diseases those with long duration and limiting the routine activities of daily life.

Excess weight is associated with a significantly greater risk of developing chronic diseases and health problems that cause devastating consequences, in addition to increased mortality rates [4].

The onset of CNCDs has been related to factors such as smoking, alcohol consumption, low consumption of fruits and vegetables and high consumption of sodium and sugar [1]. Thus, diet plays an important role in the prevention and treatment of CNCDs, since it may have a positive influence, as a protective factor, or negative, as a risk factor, in the pathogenesis of these diseases [5].

Numerous diets are recommended in an attempt to combat CNCDs, whether in the preventive or control setting. Food and nutrition organizations in different countries set guidelines for healthy diets. In parallel, there is a growing popularity of "fad diets" that are spelled out in magazines and social media, especially appealing for quick results and with the weight loss approach. These diets generally have no scientific basis and can harm the health of those who adopt them [6].

In the field of evidence-based recommendations, there are valued food standards, regardless of country guidelines. One of the most accepted diets for the treatment and prevention of CNCD is the Mediterranean diet, which is characterized by a high intake of cereals, vegetables, fruits and olive oil; a moderate intake of fish and alcohol, mainly wine; and low intake of dairy products, meat and sweets [7]. The DASH diet (dietary approaches to stop hypertension), originally designed to control hypertension, is also mentioned. Lately, it has been advocated as a healthy eating pattern that helps to maintain weight, prevent heart disease and some cancers [8].

The Paleolithic diet has been gaining ground in the field of fad diets. It is based on food patterns of human
Paleolithic ancestors, about 2.6 million to 10,000 years ago, a period that precedes the advent of industrial agriculture and is different from today's modern society. In this period, the presence of hominins species (bipedal primates), a term previous to hominids, stood out. Food choices varied, since men were hunter-gatherers and often moved in search of food availability, which in turn varied according to geographic location and climate. However, there are universal characteristics of preagricultural hominin diets that are useful for understanding how the present Western diet may predispose modern populations to chronic diseases [9]. Although diets differed in the composition of macronutrients and in the proportion of food of animal and vegetable origin, there was a relatively common point in relation to exclusions, given the lack of some types of food in that period, such as dairy products, salt, alcohol, sugar, cereals and processed products $[10,11]$.

The Paleolithic diet has become so popular that it has led to the development of clinical trials evaluating its usefulness. It even deserved a recent systematic review with meta-analysis on its applicability in metabolic syndrome [12]. However, there have been conflicting results, some noting the positive effects of the Paleolithic diet on reducing the risk of diabetes, cancer, metabolic syndrome, cardiovascular diseases and type 2 diabetes $[13,14,12]$, others mentioning deleterious effects [15], and others proving no effect [16].

The present study aims to analyze the influence of the Paleolithic diet with focusing on anthropometric (weight, body mass index and waist circumference) through a systematic review with meta-analysis.

\section{Methodology}

The following question was used to perform the systematic review: What is the effect of the Paleolithic diet on anthropometric parameters (weight, body mass index and waist circumference) compared to other control diets based on recommendations in adults?

Only studies involving humans were included. The research included randomized studies on the use of the Paleolithic diet for prevention and control of CNCD, and published in Portuguese, English or Spanish. The definition of chronic diseases was in accordance with the IOM classification (2012) [3].

The PRISMA-P systematic review protocol was used $[17,18]$ and the study was registered in the PROSPERO platform under number CRD42015027849.

The search was performed until March 2019, and were found publications covering the period between 1969 and 2019. All studies found in the search were used, regardless of the date of publication.

The initial strategy for searching for descriptors or keywords included an initial search in MeSH (Medical 
Subject Headings), which has the controlled vocabulary for indexing articles used in PubMed. Then, the following descriptors were investigated, and based on the only systematic review performed with the Paleolithic diet by Manheimer et al. (2015) [7]:

a) Related to the diet: paleolithic nutrition; palaeolithic nutrition; paleolithic diet; palaeolithic diet; paleolithic-type diet; palaeolithic-type diet; paleonutrition; palaeonutrition; paleo diet; palaeo diet; caveman diet; stone age diet; hunter gatherer diet; caveman cuisine; primal diet; evolution diet; primitive diet; ancestral human diet.

b) Related to the type of study and subjects studied: randomized controlled trial; controlled clinical trial; randomized; placebo; drug therapy; randomly; trial; groups; humans.

Using the descriptors found, the following databases were searched: Latin American and Caribbean Literature in Health Sciences (LILACS), Public Medline (PubMed), Scientific Electronic Library Online (Scielo), Science Direct, Medical Literature Analysis and Retrieval System Online (Medline), Web of Science and SciVerse Scopus (Scopus). Boolean operators (OR or AND) were applied: OR was used to select articles containing any of the terms; AND was used to select only articles containing both descriptors [19].

Two authors independently reviewed the studies identified in the search according to inclusion and exclusion criteria.

The process of selection and cataloging of studies consisted of three stages called filters.

In the first screening, after reading of title and abstract, were selected articles on the theme that answered the two key questions: "Was the study conducted with humans?" and "Does the study evaluate the relationship of adopting the Paleolithic diet in the prevention and control of CNCD?". When title and abstract were not enlightening, the article was searched in its entirety. This evaluation was done by two researchers independently. After this screening, each researcher presented a list of potential articles. The two lists were compared, and from the results was constructed a single list. In case of divergence, the article was evaluated by a third researcher.

The second filter was the stage of data extraction by using a form containing the following items: title, author, year of publication, city, type of study, beginning of study, objective, inclusion criterion, exclusion criterion, sex, age, diet, statistical analysis employed, results, and conclusion. Data was entered into the Excel program.

The third filter included a selection of publications based on quality criteria. For this, the GRADE (Grading of Recommendations Assessment, Development and Evaluation) system was used to evaluate the quality and strength of recommendations [20].

A statistical test of heterogeneity was performed for the selected studies. It was estimated by the Cochran Q test and $\mathrm{I}^{2}$ statistic. The heterogeneity was confirmed with a significance level of $p \leq 0.10$. The $\mathrm{I}^{2}$ statistic describes the percentage of total variation of point estimates that can be attributed to the heterogeneity. For the $\mathrm{I}^{2}$ metric, were considered low, moderate and high values, and percentages of 25,50 and $75 \%$, respectively. Then, forest plot graphs were analyzed to examine the overall effect and evaluate the publication bias [21]. The summary measure was performed in Review Manager 5 (RevMan 5), and fixed effects were evaluated for weight, body mass index (BMI) and waist circumference (WC).

\section{Results}

With the described research strategy were found 1224 articles. Based on exclusion criteria, the following were excluded: 12 articles because they were in another language (other than Portuguese, English and Spanish), five articles conducted on animals, and 136 articles not found in the databases.

The remaining 1088 articles were analyzed by two researchers based on the question 'Can the Paleolithic diet help in the prevention and/or control of chronic diseases in humans?'. For this review, were used only articles that described anthropometric data.

We selected 31 articles without disagreement among researchers. However, one study was characterized as case-control and six were abstracts presented at scientific events. Therefore, the systematic review included 24 articles. After the quality analysis, nine articles were included because they presented quality ranging from two to three stars and involved the control of anthropometric markers as main or secondary outcomes (weight, body mass index - BMI and/or waist circumference WC). 2 years after the review, data were updated and two more articles were included, as shown in Fig. 1.

Duration of interventions ranged from 2 weeks to 24 months, with participants assessed at baseline and after the intervention.

The Table 1 describes the articles that were included in the review. The quality analysis by using GRADE showed that in general, randomized intervention studies involving the Paleolithic diet have small samples, variations on the duration of interventions, and lack of information on the masking/blinding of the population involved. These aspects reduce the quality of the study, although there were no serious inconsistencies.

The analysis of the nine studies that analyzed anthropometric markers allowed the organization of data in three subgroups, namely variation of weight, BMI and WC. 


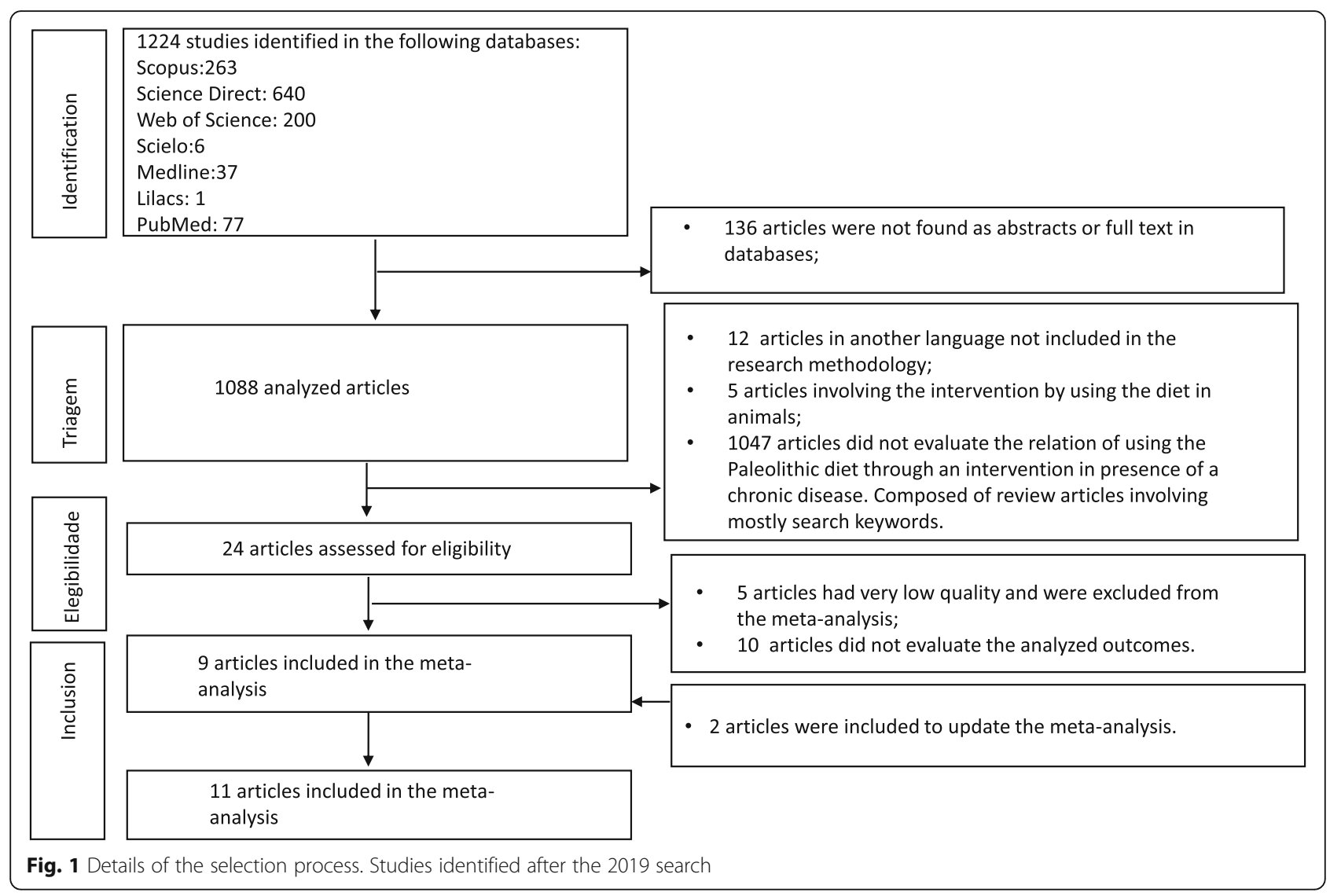

The paleo and control diets and how to measure diet compliance were also evaluated, and Table 2 shows data from studies included in this review. In most studies, were used diets based on higher consumption of vegetables, whole grains and low-fat dairy for the control group. For the Paleo diet intervention group, diets were based on fish, lean meats, eggs, vegetables, fruits, and nuts, and exclusion of cereals, dairy products and sugar. The diets given to participants were evaluated through a food record of more than 2 days. Its composition was also described.

The three markers were evaluated in five studies $[23,26,27,30,37]$; weight and WC were evaluated in three studies [40, 41, 44], and weight only was evaluated in three other studies [14, 42, 43].

Among the articles in which was performed the metaanalysis, five $(45,5 \%)$ involved women mostly in the menopausal or postmenopausal period, and was evaluated the effect of diet on weight loss [23, 26, 27, 43, 44]. There was an article on healthy women with a focus on disease prevention [41]. As for the others, two $(18,2 \%)$ clinical trials were performed with subjects with type 2 diabetes [37, 42], one $(9,1 \%)$ in heart disease patients [40], one $(9,1 \%)$ in patients with metabolic syndrome [30], and one $(9,1 \%)$ in hypercholesterolemic individuals [14].
By analyzing the body weight, was found a decrease in the mean weight $(-3.52 \mathrm{~kg})$, and the Confidence Interval (95\%) ranged from -5.26 to -1.79 . The forest plot (Fig. 2) shows a relationship between weight loss and the adoption of the Paleolithic diet $\left(\mathrm{I}^{2}=24 \%\right.$ and $\left.p=0.22\right)$.

These effects were also found in BMI, with a mean reduction of $-1.09 \mathrm{~kg} / \mathrm{m}^{2}$, Confidence Interval (95\%) from -2.03 to -0.14 . The forest plot (Fig. 3) shows no relation between BMI and the Paleolithic diet $\left(\mathrm{I}^{2}=36 \%\right.$ and $p=0.17)$. For $\mathrm{WC}$, the mean reduction was $-2.46 \mathrm{~cm}$, and for the confidence interval (95\%) from -4.28 to 0.64 , demonstrating a relationship between WC and the adoption of the Paleolithic diet $\left(\mathrm{I}^{2}=40 \%\right.$ e $\left.p=0.11\right)$, as shown in the forest plot, Fig. 4.

\section{Discussion}

The present study evaluated randomized clinical trials (RCT), which is considered a gold standard design because it is the least affected by the influence of confounding factors and biases [45].

Regardless of the RCT design, some characteristics must be observed in order to extrapolate the results of a study to a certain clinical reality. The closer the characteristics considered by the study, the more relevant the evidence becomes. 


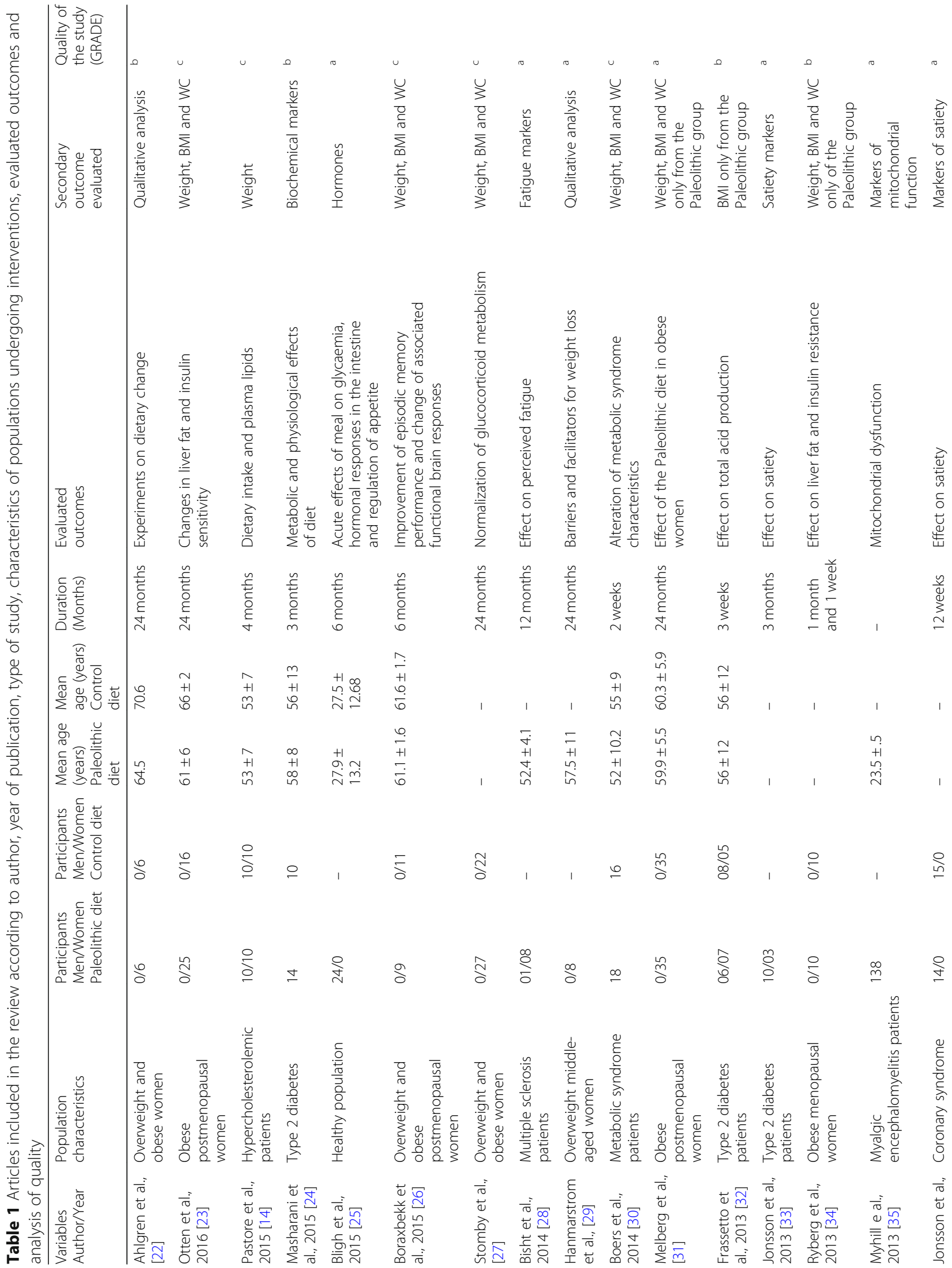




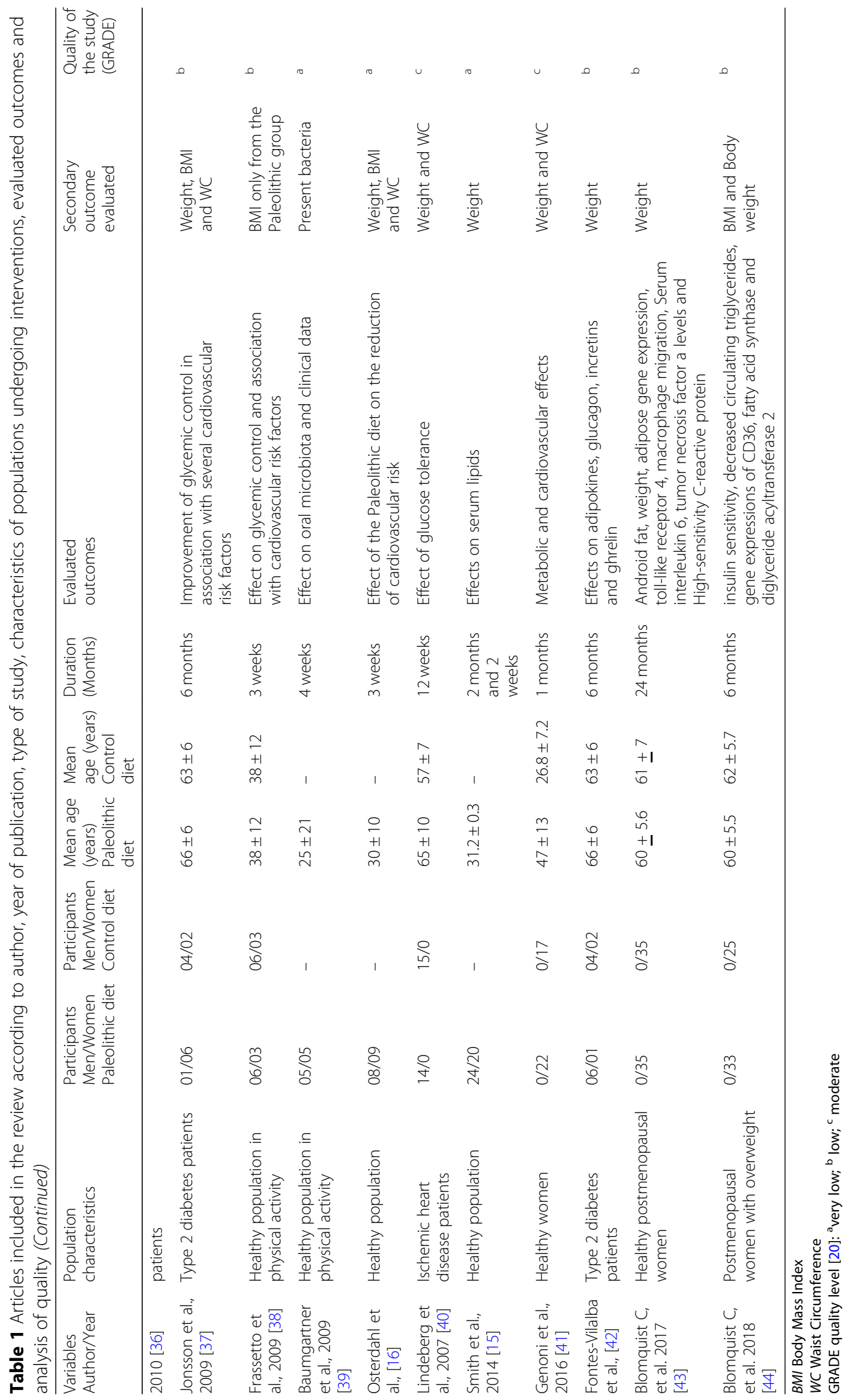




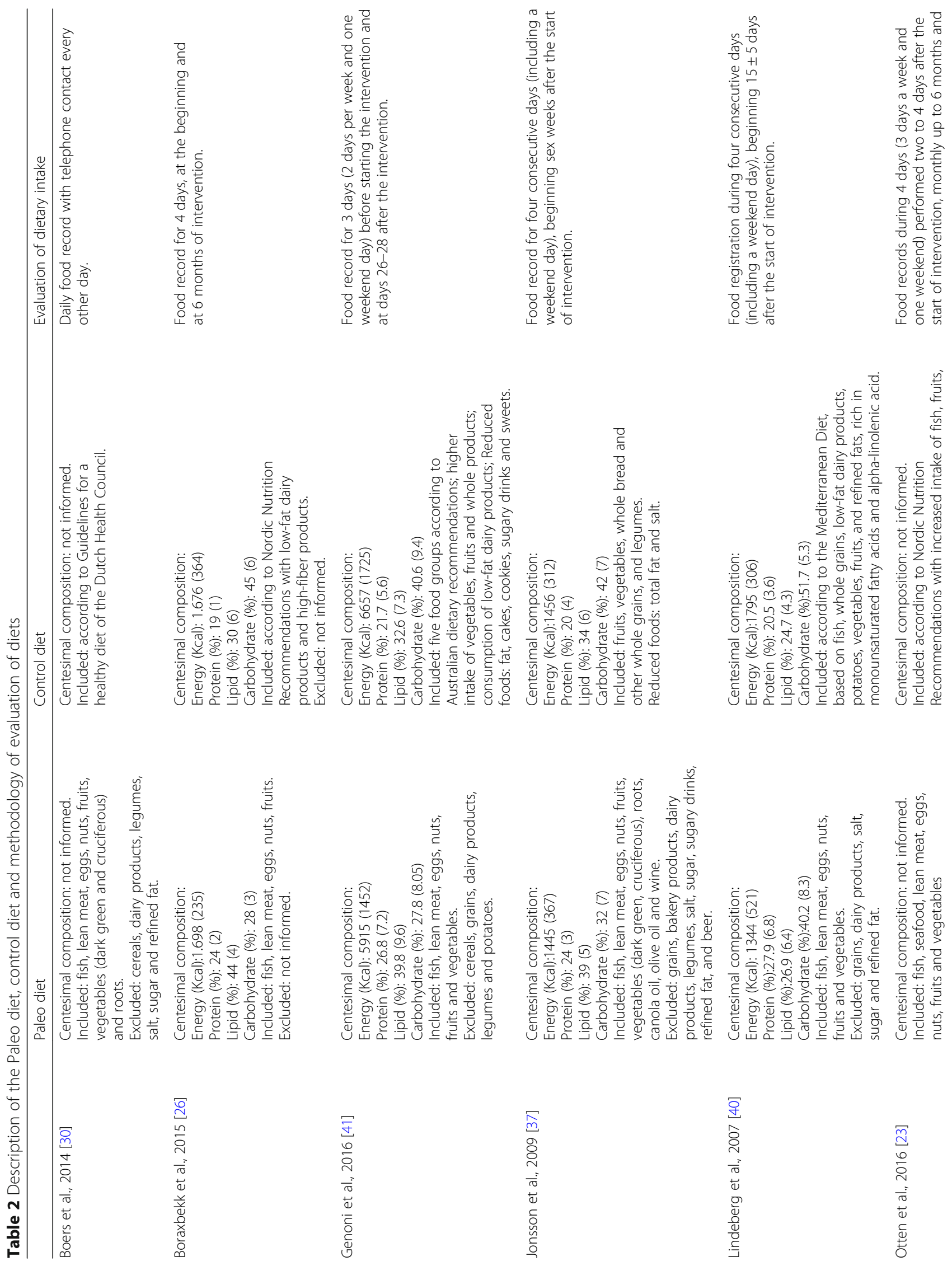




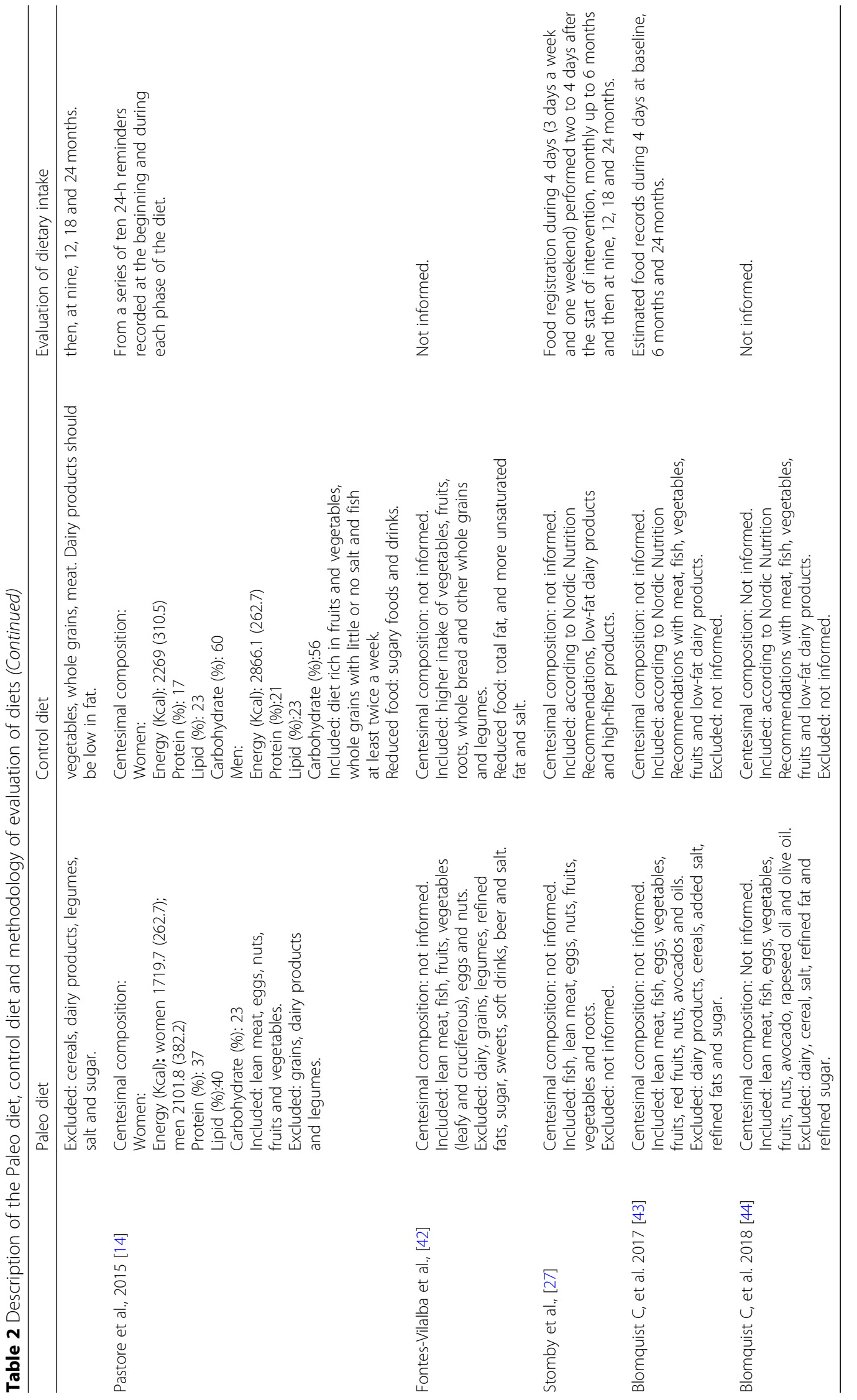




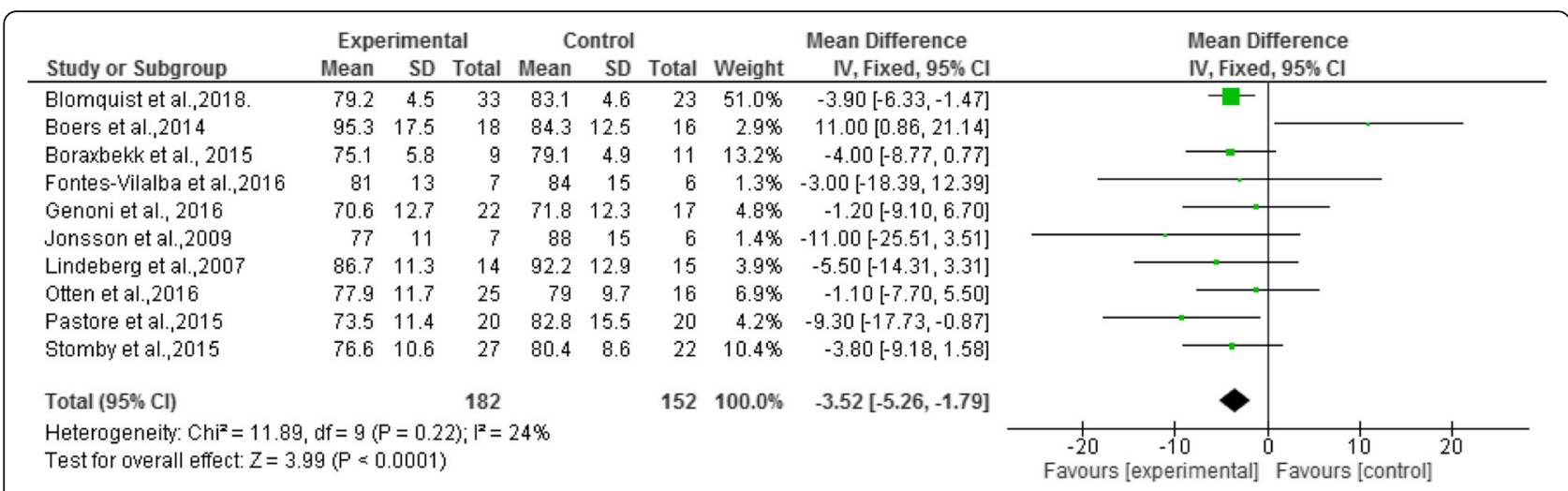

Fig. 2 Forest plot - Mean body weight differences of a population participating in a random clinical trial using the Paleolithic diet

Four basic aspects specifically determine validity, namely: participants, interventions, environment, and outcomes. With respect to participants, it is important that characteristics are close to those of the population of interest. Aspects such as age, sex, severity of disease, risk factors and associated comorbidities should be carefully considered [35]. In controlled studies, the control group and the intervention group were similar regarding age, sex and health condition. The $\mathrm{I}^{2}$ metrics of the eleven studies included was 24,36 and $40 \%$ for weight, $\mathrm{BMI}$ and WC, respectively, showing homogeneity mainly in relation to weight.

When comparing the eleven studies, the population groups differed significantly in clinical characteristics, since individuals were diabetic, hypercholesterolemic, obese, healthy and with metabolic syndrome.

The size of samples evaluated in the included studies could be considered small, as the largest intervention had 41 participants. Larger samples allow better identification of relevant effects from the clinical and public health point of view, albeit of small magnitude [23].

Interventions ranged from 2 weeks to 24 months. The analyzed studies indicate a relation between the positive results of the Paleolithic diet and the short duration of the intervention, and its beneficial effects on metabolism are reduced as the intervention continues. In the studies, the sixth month appeared as the time to obtain better results, as also observed by Otten et al. (2016) [23] and Stomby et al. (2015) [27].

The eleven studies analyzed the body weight variation throughout the intervention of Paleolithic diet, and better results were found among overweight and obese women [26, 27]. The study by Otten et al. (2016) [23] also had the same population profile but found lower weight loss.

A fact limiting the verification of effects is the initial difference in the analyzed variable when comparing the two types of diets, as in the study by Boers et al. (2014) [30], in which the group adopting an evidence-supported diet had a lower initial mean weight than the group adopting the Paleolithic diet. This study, in particular, also had a very short duration ( 2 weeks), and this may have influenced the findings.

The BMI outcome was evaluated in six studies and was associated with the adoption of the Paleolithic diet $(p=0.02)$. The study with the best findings in relation to this outcome was that of Boraxbekk et al. (2015) [26], which involved overweight and obese women and lasted for 6 months. Of the six studies involving BMI, all showed a significant $(p<0.05)$ reduction of this anthropometric marker when analyzed alone, without comparison to the group that adopted the other diet.

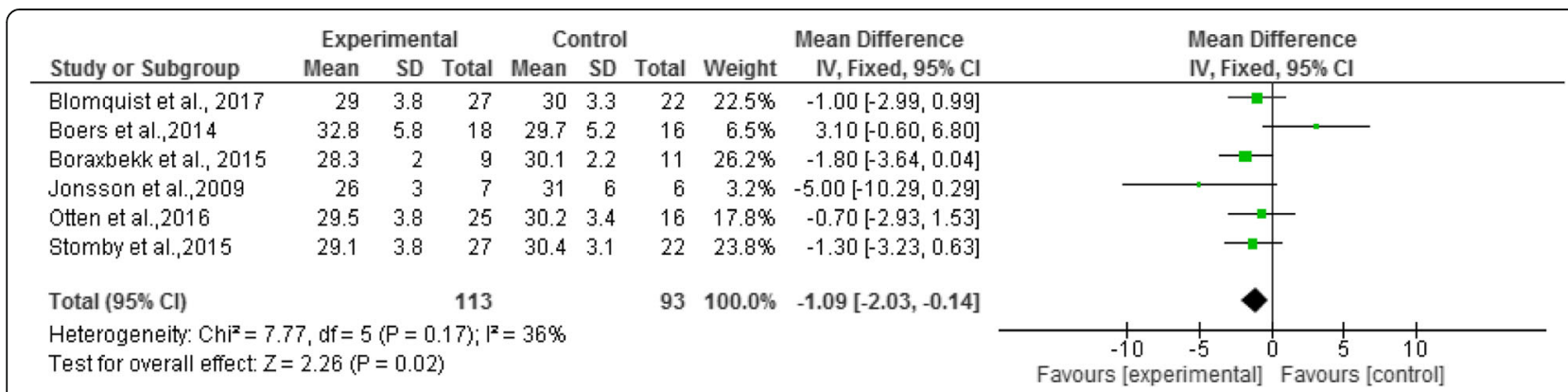

Fig. 3 Forest plot - Mean differences of Body Mass Index (BMI) of a population participating in a randomized clinical trial using the Paleolithic diet 


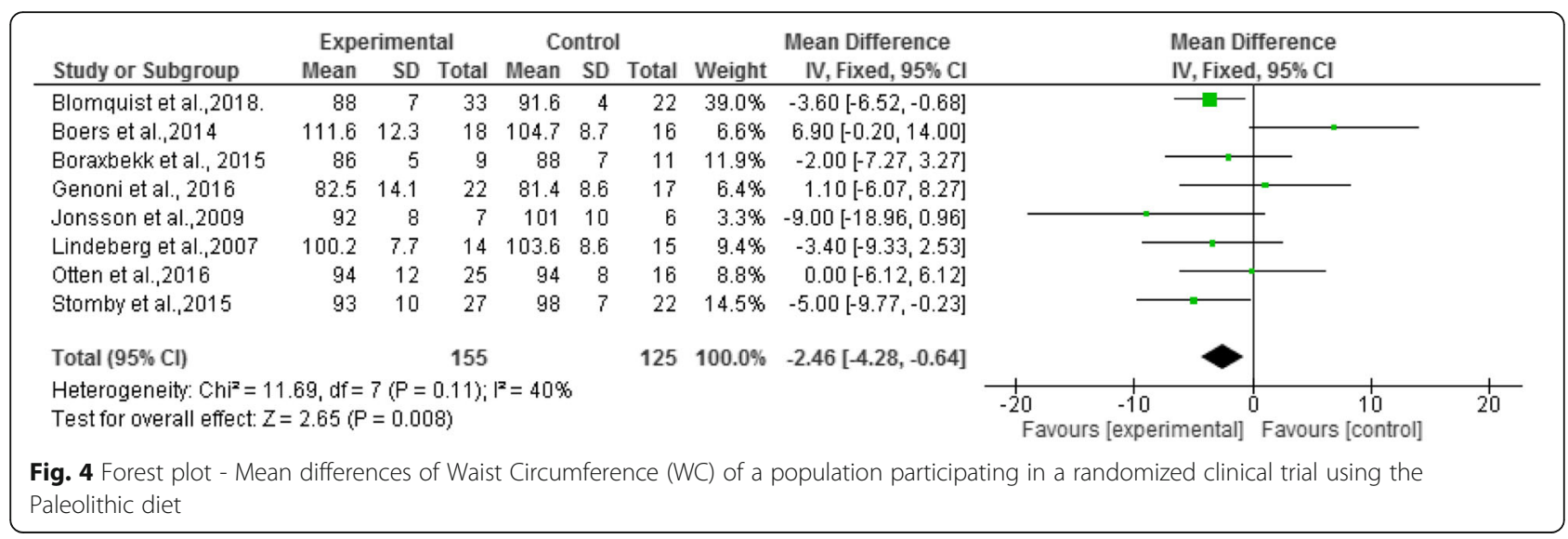

In eight studies, waist circumference was associated with the adoption of the Paleolithic diet $(p=0.008)$. In the study by Boraxbekk et al. (2015) [26], this measurement decreased, which is in line with results of weight reduction and improvement of BMI. The effect found in the study by Otten et al. (2016) [23] was different, and indicated weight reduction and increased WC. This marker was evaluated by Manheimer et al., 2015 [12], who found a significant reduction in waist circumference $\left(\mathrm{I}^{2}=52 \%\right)$. In this outcome, the highest weight was from the study by Blomquist et al., 2018 [43].

The results of this study were significant for weight loss, BMI and waist circumference. A possible hypothesis to explain the effect of the Paleolithic diet on weight loss, is its satietogenic effect, as verified by Bligh et al., 2015 [38], who tested the acute effect of meals based on the Paleolithic diet on biochemical markers of satiety compared to a guideline-based diet [1]. Twenty-four men aged between 18 and 60 years old were healthy and had BMI between 18 and $27 \mathrm{Kg} / \mathrm{m}^{2}$. Concentrations of glucagon-1 (GLP-1) and Peptide YY (PYY) peptides were significantly increased over $180 \mathrm{~min}$ with the use of different formulations of the Paleolithic diet compared to the control diet.

This meta-analysis was focused on anthropometric markers by evidencing favorable effects of adopting the Paleolithic diet to body weight BMI and waist circunference. The study adds to the review by Manheimer et al. (2015), in which was found a significant improvement in some markers of metabolic syndrome when adopting this diet.

For future reviews, a greater number of quality clinical trials is required for better definitions. A longer follow-up and larger sample size are recommended in future clinical trials on the subject, besides a greater standardization of the Paleolithic diet used. Studies presenting the biochemical results and proven pathophysiological mechanisms of this diet are also scarce.

\section{Conclusion}

The adoption of the Paleolithic diet is associated with weight loss, BMI and WC. Still, this diet can influence the prevention and control of chronic diseases, since excess weight is a risk factor for their development.

In addition to any food fads, the present study points to the need for further research to evaluate other effects in controlled and well-designed studies regarding sociodemographic, economic, cultural and clinical characteristics of the selected sample, time of adoption of the diet, and type of Paleolithic diet used.

\section{Abbreviations}

BMl: Body mass index; CNCD: Chronic noncommunicable diseases; DASH: Dietary approaches to stop hypertension; GLP-1: Glucagon-1; GRADE: Grading of Recommendations Assessment, Development and Evaluation; IOM: Institute of Medicine; LILACS: Latin American and Caribbean Literature in Health Sciences; Medline: Medical Literature Analysis and Retrieval System Online; MeSH: Medical Subject Headings; PubMed: Public Medline; PYY: Peptide YY; RCT: Randomized clinical trials; Scielo: Scientific Electronic Library Online; WC: Waist circumference; WHO: World Health Organization

\section{Acknowledgements}

Not applicable.

\section{Authors' contributions}

EVAdeM: participated in designing the project, collecting and analyzing the data, writing the article. Thus, you state that you had sufficient participation in the work to assume responsibility for the total content. HAdeCS: participated in the project design, data analysis, article writing, critical review of the work and approved the final version. Thus, you state that you had sufficient participation in the work to assume responsibility for the total content. AAFC: collaborated / guided from the design of the project, critical review of the work until approval of the final version. Thus, you state that you had sufficient participation in the work to assume responsibility for the total content. NdeAP: participated in designing the project, collecting and analyzing the data, writing the article. Thus, you state that you had sufficient participation in the work to assume responsibility for the total content. FOB: participated in designing the project, collecting and analyzing the data, writing the article. Thus, you state that you had sufficient participation in the work to assume responsibility for the total content. TMMM: collaborated / guided from the design of the project, critical review of the work until approval of the final version. Thus, you state that you had sufficient participation in the work to assume responsibility for the total content. ACCdes: collaborated / guided from the design of the project, critical review of the work until approval of the final version. Thus, you state that you had 
sufficient participation in the work to assume responsibility for the total content. SPMA: collaborated / guided from the design of the project, critical review of the work until approval of the final version. Thus, you state that you had sufficient participation in the work to assume responsibility for the total content. All authors read and approved the final manuscript.

\section{Funding}

Study carried out without funding.

\section{Availability of data and materials}

Data sets used and / or archived during the occurrence cycle are available without reasonable collection.

\section{Ethics approval and consent to participate}

Not applicable.

\section{Consent for publication}

Not applicable.

\section{Competing interests}

The authors declare that they have no conflicting interests.

\section{Author details}

'Postgraduate Program in Colletive Health, Universidade Estadual do Ceará (UECE), Fortaleza, Brazil. ${ }^{2}$ Nutrition course, Universidade de Fortaleza (UNIFOR), Fortaleza, Brazil. ${ }^{3}$ Nutrition in Public Health, Faculdade Saúde Pública, Universidade de São Paulo (USP), São Paulo, Brazil. " ${ }^{4}$ ublic Health, Universidade de São Paulo (USP), São Paulo, Brazil. ${ }^{5}$ Clinical Care in Health, Universidade Federal do Ceará (UFC), Fortaleza, Brazil. ${ }^{6}$ Nucleus of Research and Development of Medications, Universidade Federal do Ceará, Fortaleza, Brazil. ${ }^{7}$ Collective Health, Universidade Federal do Maranhão, São Luís, Brazil. ${ }^{8}$ Postgraduate Program in Collective Health and Academic Master's in Nutrition and Health, Universidade Estadual do Ceará, Fortaleza, Brazil.

Received: 23 July 2018 Accepted: 7 June 2019

Published online: 23 July 2019

\section{References}

1. WHO. Library cataloguing-in-publication data global status report on noncommunicable diseases 2014. 1.Chronic disease - prevention and control. 2.Chronic disease - epidemiology. 3.Chronic disease - mortality. 4.Cost of illness. 5.Delivery of health care. Geneva: World Health Organization; 2014.

2. OMS. Prevenção de doenças crônicas: um investimento vital. Brasília: Organização Mundial da Saúde; 2005.

3. Institute of Medicine. Living well with chronic disease: a call for public health action. Washington, D.C.: The National Academic Press; 2012.

4. WHO. Diet, nutrition and the prevention of chronic diseases. Geneva: World Health Organization; 2003.

5. Ahmed T, Hsboubi N. Assessment and management of nutrition in older people and its importance to health. Clin Interv Aging. 2010;9;5:207-16.

6. Friedman M. The paleo diet and the insanity workout dominated Google search in 2014. http://www.redbookmag.com/body/news/a19569/paleodietinsanity workout-top-google-search-2014/ (Acesso em setembro de 2016).

7. Salas-Salvadó J, Fernández-Ballart J, Ros E, Martínez-González MA, Fitó M, Estruch $\mathrm{R}$, et al. Effect of a Mediterranean diet supplemented with nuts on metabolic syndrome status: one year results of the PREDIMED randomized trial. Arch Intern Med. 2008;168(22):2449-58.

8. US News \& World Reports: best and healthiest diet plan. The DASH diet eating plan. https://health.usnews.com/best-diet/dash-diet. Accessed June 2019.

9. Cordain L, Eaton B, Sebastian A, Mann N, Lindeberg S, Watkins BA, O'Keefe JH, Brand-Miller J. Origins and evolution of the Western diet: health implications for the 21 st. United States of America: Western Dietary Origins; 2005.

10. Cordain L, Miller JB, Eaton SB, Mann N, Holt SH, Speth JD. Plant-animal subsistence ratios and macronutrient energy estimations in worldwide hunter-gatherer diets. Am J Clin Nutr. 2000;71(3):682-92.

11. Cordain L, Eaton SB, Miller JB, Mann N, Hill K. The paradoxical nature of hunter-gatherer diets: meat-based, yet non-atherogenic. Eur J Clin Nutr. 2002;56:42-52.

12. Manheimer EW, Zuuren EJV, Fedororowicz Z. Paleolithic nutrition for metabolic syndrome: systematic review and meta-analysis. Am J Clin Nutr. 2015;102:922-32
13. Kowalshi LM, Bujko J. Evaluation of biological and clinical potential of paleolithic diet. Rocz Panstw Zakl Hig. 2012;63(1):9-15.

14. Pastore RL, Brooks JT, Carbone JW. Paleolithic nutrition improves plasma lipid concentrations of hypercholesterolemic adults to a greater extent than traditional heart-healthy dietary recommendations. Nutr Res. 2015; 35:474-9.

15. Smith MM, Trexler ET, Sommer AJ, Starkoff BE, Devor ST. Unrestricted Paleolithic diet is associated with unfavorable changes to blood lipids in healthy subjects. Int J Exerc Sci. 2014;7(2):128-39.

16. Osterdahl MO, Kocturk T, Koochek A, Wandell PE. Effects of a short-term intervention with a paleolithic diet in healthy volunteers. Eur J Clin Nutr. 2008;62(5):682-5.

17. Shamseer L, Moher D, Clarke M, Ghersi D, Liberati A, Petticrew M, et al. Preferred reporting items for systematic review and meta-analysis protocols (PRISMA-P) 2015: elaboration and explanation. BMJ. 2015;349:97647.

18. Moher D, Shamseer L, Clarke M, Ghersi D, Liberati A, Petticrew M, et al. Preferred reporting items for systematic review and meta-analysis protocols (PRISMA-P) 2015 statement. Syst Ver. 2015;4:1.

19. Fuchs SC, Paim BS. Revisão Sistemática de Estudos Observacionais com Metanálise. Revista HCPA. 2010;20(3):294-301.

20. Balshem $\mathrm{H}$, et al. Grade guidelines: 3 rating the quality of evidence. J Clin Epidemiol. 2011;64(4):401-6.

21. Higgins JP, Thompson SG, Deeks JJ, Altman DG. Measuring inconsistency in meta-analyses. BMJ. 2003;327(7414):557-60.

22. Ahlgren C, Hammarström A, Sandberg S, Lindahl B, Olsson T, Larsson C, Fjellman-Wiklund A. Engagement in new dietary habits-obese Women's experiences from participating in a 2-year diet intervention. Int J Behav Med. 2015;23(1):84-93.

23. Otten J, Mellberg C, Ryberg M, Sandberg S, Kullberg J, Lindahl B, et al. Strong and persistent effect on liver fat with a Paleolithic diet during a twoyear intervention. Int J Obes. 2016;40(5):747-53.

24. Masharani U, Sherchan P, Schloetter M, Startford S, Xiao A, Sebastian A, et al. Metabolic and physiologic effects from consuming a hunter-gatherer (Paleolithic)-type diet in type 2 diabetes. Eur J Clin Nutr. 2015:69(8):944-8.

25. Bligh HF, Godsland IF, Frost G, Hunter KJ, Murray P, MacAulay K, et al. Plantrich mixed meals based on Palaeolithic diet principles have a dramatic impact on incretin, peptide $Y Y$ and satiety response, but show little effect on glucose andinsulinhomeostasis: $\mathrm{Na}$ acute-effects randomised study. $\mathrm{Br} J$ Nutr. 2015;113(4):574-84

26. Boraxbekk CJ, Stomby A, Ryberg M, Lindahl B, Larsson C, Nyberg L, et al. Diet-induced weight loss alters functional brain responses during an episodic memory task. Obes Facts. 2015;8(4):261-72.

27. Stomby A, Simonyte K, Mellberg C, Ryberg M, Stimson RH, Larssom C, et al. Diet-induced weight loss has chronic tissue-specific effects on glucocorticoid metabolism in overweight postmenopausal women. International. Int J Obes. 2015;39(5):814-9.

28. Bisht B, Darling WG, Grossmann RE, Shivapour ET, Lutgendorf SK, Snetselaar $L G$, et al. A multimodal intervention for patients with secondary progressive multiple sclerosis: feasibility and effect on fatique. J Altern Complement Med. 2014;20(5):347-55.

29. Hammarström A, Wiklund AF, Lindahl B, Larsson C, Ahlgren C. Experiences of barriers and facilitators to weight-loss in a diet intervention - a qualitative study of women in northern Sweden. BMC Womens Health. 2014:14:59.

30. Boers I, Muskiet FA, Berkelaar E, Schut E, Penders R, Hoenderdos K, et al. Favourable effects of consuming a Palaeolithic-type diet on characteristics of the metabolic syndrome: a randomized controlled pilot-study. Lipids Health Dis. 2014;13:160.

31. Mellberg C, Sandberg S, Ryberg M, Eriksson M, Brage S, Larsson C, et al. Long-term effects of a Palaeolithic-type diet in obese postmenopausal women: a 2-year randomized trial. Eur J Clin Nutr. 2014;68(3):350-7.

32. Frassetto LA, Shi L, Schloetter M, Sebastian A, Remer T. Established dietary estimates of net acid production do not predict measured net acid excretion in patients with type 2 diabetes on Paleolithic-Hunter-gatherertype diets. Eur J Clin Nutr. 2013;67(9):899-903.

33. OJönsson T, Granfeldt Y, Lindeberg S, Hallberg AC. Subjective satiety and other experiences of a Paleolithic diet comparedto a diabetes diet in patientswithtype 2 diabetes. Nutr J. 2013;12:105.

34. Ryberg M, Sandberg S, Mellberg C, Stegle O, Lindahl B, Larsson C, et al A Palaeolithic-type diet causes strong tissue-specific effects on ectopic fat deposition in obese postmenopausal women. J Intern Med. 2013; 274(1):67-76 
35. Myhill S, Booth NE, McLaren-Howard J. Targeting mitochondrial dysfunction in the treatment of Myalgic encephalomyelitis/chronic fatigue syndrome (ME/CFS). Int J Clin Exp Med. 2013;6(1):1-15.

36. Jönsson T, Grantfeld T, Erlanson-Arbertsson C, Ahrén B, Lindeberg S. A paleolithic diet is more satiating per calorie than a mediterranean-like diet in individuals with ischemic heart disease. Nutr Metab. 2010;7:85.

37. Jönsson T, Grantfeld T, Erlanson-Arbertsson C, Ahrén B. Beneficial effects of a Paleolithic diet on cardiovascular risk factors in type 2 diabetes: a randomized cross-over pilot study. Cardiovasc Diabetol. 2009;8:35.

38. Frassetto LA, Schloetter M, Mietus-Synder M, Morris RC, Sebastian A. Metabolic and physiologic improvements from consuming a paleolithic, hunter-gatherer type diet. Eur J Clin Nutr. 2009;63(8):947-55.

39. Baumgartner S, Imfeld T, Schicht O, Rath S, Persson RE, Persson GR. The impact of the stone age diet on gingival conditions in the absence of oral hygiene. J Periodontol. 2009;80(5):759-68.

40. Lindeberg S, Jönsson T, Granfeld Y, Borgstrand E, Sjöström K, Ahrén B. A Palaeolithic diet improves glucose tolerance more than a Mediterraneanlike diet in individuals with ischaemic heart disease. Diabetol. 2007;50(9):1795-807.

41. Genoni A, Lyons-Wall P, Lo J, Devine A. Cardiovascular, metabolic effects and dietary composition of a ad-libitum Paleolithic vs. Australian guide to healthy eating diets: a 4-week randomised trial. Nutrients. 2016;8(5).

42. Fontes-Villalba M, Lindeberg S, Granfeld Y, Knop FK, Memon AA, CarreraBastos $\mathrm{P}$, et al. Palaeolithic diet decreases fasting plasma leptin concentrations more than a diabetes diet in patients with type 2 diabetes: a randomised cross-over trial. Cardiovasc Diabetol. 2016;15:80.

43. Blomquist $\mathrm{C}$, et al. Decreased lipogenesis-promoting factors in adipose tissue in postmenopausal women with overweight on a Paleolithic-type diet. Eur J Nutr. 2018

44. Blomquist C, et al. Attenuated low-grade inflammation following long-term dietary intervention in postmenopausal women with obesity. Obesity 2017; 25(5):892-900

45. Albrektsson T, Wennerberg A. Oral implantsurfaces: Part 2 -review focusing on clinical knowledge of different surfaces. Int. j. prosthodont. 2004;17:544-64.

\section{Publisher's Note}

Springer Nature remains neutral with regard to jurisdictional claims in published maps and institutional affiliations.

Ready to submit your research? Choose BMC and benefit from:

- fast, convenient online submission

- thorough peer review by experienced researchers in your field

- rapid publication on acceptance

- support for research data, including large and complex data types

- gold Open Access which fosters wider collaboration and increased citations

- maximum visibility for your research: over $100 \mathrm{M}$ website views per year

At $\mathrm{BMC}$, research is always in progress.

Learn more biomedcentral.com/submissions 